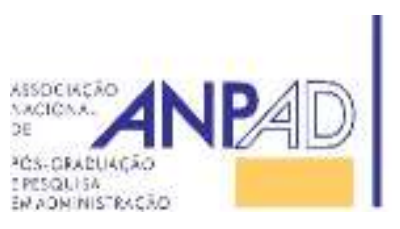
Available online at http://www.anpad.org.br/bar
BAR, Rio de Janeiro, v. 13, n. 1, art. 2, pp. 19-32, Jan./Mar. 2016 http://dx.doi.org/10.1590/1807-7692bar2016160020

\title{
Improving Consumer Decisions: The Conscious Use of Primes as Performance Enhancers
}

\author{
Leonardo Nicolao ${ }^{1}$ \\ Eric Yorkston ${ }^{2}$ \\ Deanne Brocato ${ }^{3}$ \\ Vinicius Andrade Brei ${ }^{1}$
}

Universidade Federal do Rio Grande do Sul ${ }^{1}$

Texas Christian University ${ }^{2}$

Utah State University ${ }^{3}$

Received 12 February 2016; received in revised form 5 April 2016; accepted 7 April 2016; published online 28 April 2016. 


\begin{abstract}
Through this article we examine ways through which consumers can take advantage of marketers' priming attempts and make better decisions. Specifically, we investigate what happens when individuals are made aware of primes that may potentially improve their performance. Using an Embedded Figures Test, we demonstrate that individuals can be consciously primed into an analytic thinking mindset and perform better when they believe that the prime will enhance performance. Individuals are able to successfully ignore the prime when they believe that the prime hinders performance. Utilizing both holistic and analytic primes and by alternating the valence of the prime's potential outcome, we are able to disentangle the conscious effects of primes from demand effects. We discuss how these findings may lead to and suggest avenues for future research.
\end{abstract}

Key words: consumer decision process; positive marketing; priming, awareness; analytic versus holistic thinking. 


\section{Introduction}

Individuals make different decisions to solve their consumption needs in a daily basis. These decisions are highly dynamic, influenced by contextual factors and individual psychological processes. At the core of such processes, and of much of research in Consumer Behavior, is the interplay between affective and cognitive aspects (Shiv \& Fedorikhin, 1999). This manuscript resides in the realm of the latter aspect, demonstrating how consumers (and companies) can use cognitive primes to improve their performance on consumption decisions.

Individuals are regularly exposed to a myriad of consumer-related cognitive tasks. These tasks can be general, such as how to spend their budget in a supermarket (Heath \& Soll, 1996), or more specific, such as the choice of an individual product or brand among many different options available on the market (Schwartz, 2009). In all these tasks, consumers can face different types of stimuli, such as visual, auditory, olfactory, tactile, gustative; all of them being able to temporarily activate a response tendency. These stimuli that direct someone towards a certain response or behavior tendency are known as primes (Lashley, 1951; Storms, 1958).

Priming has a long-standing history in the marketing literature and, specifically, in consumer behavior research (for a thorough review, see Janiszewski \& Wyer, 2014). Its effects vary from how favorably individuals respond to ethnic spokespeople when primed with ethnic self-awareness (Forehand \& Deshpandé, 2001) to how ceiling height influences consumers' type of cognitive processing (Meyers-Levy \& Zhu, 2007). Such effects are often depicted by the popular business press as detrimental and manipulative (Lindstrom, 2011).

In this paper we do not deny that priming frequently leads to undesirable outcomes (e.g., advertising that makes people buy things they do not need), but rather, we try to provide examples of when priming may be utilized to help consumers. Our objective is to explore situations when priming can lead to positive outcomes, better decisions, and focused thinking. Specifically, we show that awareness of priming tasks and their intended effects helps consumers to process information. As we discuss in the literature review, this effect is counterintuitive, yet positive, leading to better decisions.

For consumers, better decisions are directly related to increased control, empowerment, and happiness (Desmeules, 2002; Dhar \& Kim, 2007; Wathieu et al., 2002). Positive priming strategies can make cognitive tasks more efficient and helpful, not only to consumers, but also to organizations. For example, they can be used to improve different marketing actions, such as advertising that is more informative, clearer retailing signalization, and better product recommendations. These contributions may add to the literature of the nascent field of Positive Marketing, which considers that the job of business is to provide products, services, experiences and ideas that will help people improve their lives and companies reach sustainable results (Lerman \& Shefrin, 2015).

The paper unfolds as follows. First, we review the literature on priming awareness, and its correction. Next, we present two experimental studies that provide evidence that awareness of the priming not only does not necessarily lead to correction or contrast effects, but can actually facilitate how people control intended effects. We conclude discussing theoretical implications to consumer decision literature and consequences to marketing practice.

\section{Priming and Awareness}

Numerous environmental factors below the surface of our conscious awareness often play roles in forming our judgments and influencing which goals we pursue (Bargh \& Chartrand, 1999). These factors, visual, auditory, olfactory or other, can temporarily activate a response tendency or, in other words, prime a response tendency (Lashley, 1951; Storms, 1958). Activation often happens through a 
priming task where individuals are engaged in an ostensibly unrelated activity and are thereby unaware that concepts have been activated that will later influence subsequent tasks or judgments.

The role of awareness on priming effectiveness has been for a long time, topic of inquiry (see Bargh, 1994, for a review). Awareness, or lack thereof, can influence the effectiveness of a priming task in two distinct forms: (a) an individual is unaware of the priming stimulus, or (b) an individual is unaware of the effects of the priming stimulus on subsequent priming tasks (Bargh, 1994). Unawareness of the priming stimulus often manifests itself when information is presented subliminally (or preconsciously) to activate either a matching trait in memory or a related goal (Bargh, 1989). For example, in one of the early mere-exposure effect studies, Kunst-Wilson and Zajonc (1980) found that repeated subliminal exposure to a stimulus increases preference for it through increased familiarity.

Interestingly, unawareness of priming stimulus is not a necessary condition for successful priming. Priming effects have been found even when priming stimuli were presented to individuals' conscious awareness (Chartrand \& Bargh, 1996). For example, Kettle and Häubl (2011) pointed out a significant and predictable effect of an individual's signature on a number of subsequent effects. Signing her own name primes self-identity related concepts which lead to changes in behavior, such as becoming more engaged while shopping in a product domain with which she closely identifies. She can also conform with her in-group when making consumption choices in domains that are relevant to signaling one's identity. The signature and the act of signing a name are happening at a supraliminal level; individuals were aware of their signature. However, in these cases, although participants are aware of the prime itself, they are unaware that it may cause any potential effects.

There seems to be a consensus in the literature that, although awareness perception of priming stimuli might not hinder priming effects, awareness of the potential influence of the priming stimuli on subsequent information processing is detrimental (Bargh, 1992; Chartrand \& Bargh, 1996; Wyer, 2008). When individuals are made aware of the effects of priming stimuli they engage in correction, consciously or nonconsciously (Strack, Schwarz, Bless, Kübler, \& Wänke, 1993). In other words, individuals who know the effects a priming task has on their behavior or goals react in order to overcome or counteract the effect.

\section{Priming and Correction}

People are often unaware of how many implicit associations and different connections are made when a concept is activated. Consequently, people are not always aware whether or how their subsequent behavior is influenced. However, once individuals become aware of this influence, they will try to correct for it (Wyer, 2008). This same pattern of correction for biased information happens for priming attempts. When individuals are made aware that a priming task serves a purpose - influencing a subsequent task or judgment - they engage in conscious correction (Devine, 1989; Strack et al., 1993) or nonconscious correction (Laran, Dalton, \& Andrade, 2011). For example, Lepore and Brown (2002) concluded that priming high-prejudice and low-prejudice participants with the blacks category caused judgments of that same category to be respectively more negative and more positive. However, awareness of a connection between priming and impression formation tasks caused this pattern to be reversed.

This reversal caused by awareness of the influence of the priming task is found in other domains and it is often referred to as contrast effects (Lombardi, Higgins, \& Bargh, 1987; Martin, 1986; Strack et al., 1993). Researchers seem to agree that consciousness of the priming event will lead to contrast effects, or to the reversal of the intended effect.

We believe that the findings above are sound, but do not fully elucidate the value of priming. This is due to how psychologists have inherently defined and approached priming in the past, possibly due to our focus on our disease model of psychology. If environmental primes unintentionally bias our 
actions, then these are things to be corrected for with contrast effects. However, what if priming causes us to perform better or more consistently with our consumption goal, albeit unintentionally? Should we be motivated to not correct, and in fact, enhance the effect of these primes?

Actually, there is evidence of behavioral primes helping consumers achieve goals. Fitzsimons, Chartrand and Fitzsimons (2008) found that individuals primed with Apple logos were more creative than those primed with IBM logos. Similarly, Chartrand, Huber, Shiv and Tanner (2008) showed that priming individuals with the concepts of prestige and thrift has indeed led to consistent choices of prestige and thrift options, respectively. In both scenarios, the effects of priming are arguably positive and goal-consistent; they help consumers to save money and to be more creative. However, individuals are not aware of the effects of priming and hence cannot control them.

The following two experimental studies provide evidence that awareness of priming task does not necessarily lead to correction or to contrast, and that it can actually facilitate intended effects. These studies demonstrate that if a priming task's influence is consistent with an individual's goals, it may be effective even when individuals are aware of the prime and its influence. Our first study replicates the well-known effect that being primed to think analytically aids in identifying figures embedded in complex patterns. We demonstrate that this effect is amplified when individuals are made aware of the connection between the priming task and the identification task. Our second study rules out the possibility of a demand or placebo effect on Study 1. Taken together, both studies allow us to better understand how consumers can enhance their task performance and how organizations can use this knowledge to improve their marketing practice.

We have chosen the established effects of analytic and holistic thinking styles, or mindsets, as proof of concept. Previous studies (Kühnen, Hannover, \& Schubert, 2001; Monga \& John, 2007, 2008) have found that individuals can be primed to think analytically by following a task where they read a paragraph about a trip to a city and circled all the first person singular pronouns (e.g., I, me). To think holistically, individuals instead circled first person plural pronouns (e.g., we, us). This procedure maps into the established priming tasks for the activation of independent and interdependent selves (Brewer \& Gardner, 1996; Gardner, Gabriel, \& Lee, 1999; Nisbett, Peng, Choi, \& Norenzayan, 2001). In fact, Monga and John (2007) discussed that "acquiring the independent self (e.g., traits) involves developing a context-independent (analytic) mode of thinking, whereas acquiring the interdependent self (e.g., relations) involves developing a context-dependent (holistic) mode of thinking" (p. 533).

In other words, this pronoun-circling procedure relies on the activation of the concepts of analytic and holistic thinking through the indirect semantic activation of independence and interdependence, respectively. These, in turn, are made more easily accessible by the singularity and plurality of the pronouns in the task. This path from pronouns to mindsets characterizes a spreading activation perspective of the priming task (Janiszewski \& Wyer, 2014).

Monga and John $(2007,2008)$ and Kühnen, Hannover and Schubert (2001) raised that different mindsets (analytic and holistic) reflect on performance for pattern-recognition tasks. Specifically, they brought evidence that individuals who are primed with an analytical mindset are more successful at finding embedded objects in the in the Embedded Figures Test (EFT) (Horn, 1962) than those thinking holistically. We chose to replicate this effect for its consistency. We are less interested in analytical and holistic thinking styles and their effect on EFT performance and more interested in the effects of awareness on the effectiveness of a priming task.

To test our laid out assumptions, both studies will be experiments. Experimental studies allow us to control for extraneous factors, focusing on our interest variables and, hence, establishing a causeeffect relationship (Rosenthal \& Rosnow, 2007). 


\section{Study 1 - The Positive Outcomes of Priming}

\section{Method}

Participants $(\mathrm{N}=151)$ completed the first study in exchange for extra-credit in their undergraduate course. They were randomly assigned to one of the conditions of a 2 (holistic vs. analytic thinking style) x 2 (aware vs. unaware of the priming task) between-subjects design. This between-subjects design allows us to allocate our participants to one of four conditions (holistic aware, holistic unaware, analytic aware and analytic unaware), avoiding the possible demand effects that the knowledge of other conditions could bring.

We told all participants that they would be completing two tasks on visual perception: a word search task where they would circle pronouns in a paragraph and a simple recognition task in which they would find simple shapes embedded in more complex geometrical patterns. To manipulate prime awareness, we told half of the participants that completing the pronoun-circling task would change how they think and help them perform better in the subsequent embedded figures test. The unaware participants were not informed about how the completion of one task could affect their performance on the other task.

After the tasks were explained, all participants read a paragraph about a trip to a city that contained twenty pronouns, either in the first person singular (i.e. I, me) or first person plural (i.e. we, us). Participants in the holistic condition were asked to circle the first person plural pronouns, which represented the interdependent self; those in the analytic condition circled the first person singular pronouns, representing the independent self. This procedure was adapted from Kühnen et al. (2001).

All participants followed with the Embedded Figures Test (EFT) (Horn, 1962) cited above in which they had two minutes to find objects embedded in 40 pictures (one object per picture).

\section{Manipulation check}

The percentage of correctly circled pronouns was calculated for each participant for the pronouncircling task. The pronoun task was designed to be simple in order to act as a prime. Only three participants did not accurately circle all twenty pronouns. These three respondents had $95 \%$ of accuracy and they were dispersed across the conditions, remaining in the sample.

\section{Results}

EFT scores were calculated by adding up the total number of correct figures identified by each participant in our sample. Consistent with the reviewed literature, there is a significant main effect of thinking style (analytic vs. holistic) on EFT performance, $F(1,147)=16.44, p<.05, \eta_{p}^{2}=.10$, where individuals primed with the analytic thinking style identified a greater number of figures $\left(M_{\text {analytic }}=\right.$ $24.83)$ than those primed with the holistic thinking style $\left(M_{\text {holistic }}=20.93\right)$. There is also a marginally significant main effect of awareness on the total number of figures identified, $F(1,147)=3.27, p=.07$, $\eta_{p}^{2}=.02$, such that individuals who were aware of the effects of the thinking prime performed slightly better $\left(M_{\text {aware }}=23.71\right)$ than individuals who were unaware of the effects of the prime $\left(M_{\text {unaware }}=22.18\right)$. Albeit not significant, this main effect could point to possible demand effects in our manipulation. A significant two-way interaction would rule this possibility out.

Indeed, we found a significant two-way interaction between thinking style (analytic vs. holistic) and awareness of the thinking style prime (aware $v$ s. unaware) on performance in the EFT, $F(1,147)=$ $6.08, p<.05, \eta_{p}^{2}=.04$. Through a spotlight analysis (Irwin \& McClelland, 2001), we found that the difference in performance between holistic and analytic thinking styles was not significant for individuals in the unaware condition, $F(1,147)=1.30 \mathrm{~ns}$. More important, however, individuals in the 
aware, analytic condition performed significantly better than those in the aware, holistic condition, $M_{\text {aware, analytic }}=27.26, M_{\text {aware, holistic }}=20.62, F(1,147)=20.63, p<.05, \eta_{p}^{2}=.12$.

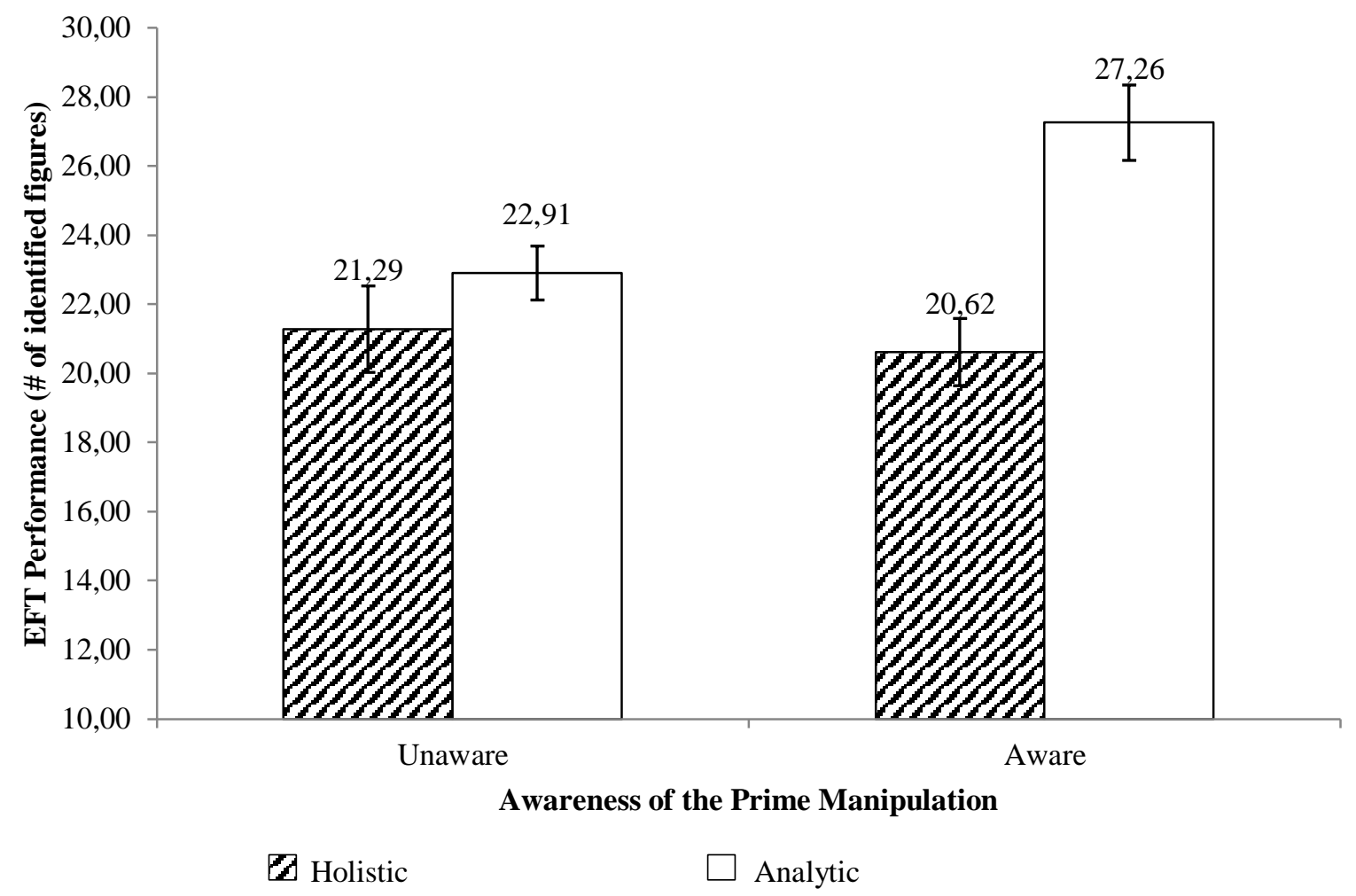

Figure 1. Performance on the Embedded Figures Test by Awareness and Thinking Style

This first study presents evidence that, contrary to what has been predicted and shown in the literature, awareness of priming attempts has the potential of amplifying instead of hindering priming effects. When told the thinking style manipulation (i.e., the pronoun-circling task) would improve their performance, individuals in the analytic thinking condition actually experienced better results in the EFT. Unlike in previous research, there is no evidence of reactance.

However, the effect of awareness on EFT performance is asymmetrical. Only individuals in the analytic condition benefited from being aware of the priming effects, $F(1,147)=9.26, p<.05, \eta_{p}^{2}=.06$. Individuals in the holistic condition performed just as well in the aware and unaware conditions, $F(1,147)=0.64, n s$. This is consistent with the original findings where only analytic thinking style increases performance at the Embedded Figures Test (Monga \& John, 2007; Nisbett et al., 2001).

Study 1 results have implications for consumer decision making. Consumers may be aware of priming attempts and strategically take advantage of them. For example, consumers who are under timepressure or overloaded and need to make many decisions may prime themselves to improve their supermarket choices, even when they are making decisions for their families (i.e., a holistic context). In this case, their self-prime should be targeted to reframing their decision from a familiar to an individual perspective. In a broader example of our effects, consumers might know that signing their name will increase commitment (Kettle \& Häubl, 2011) and, consequently, choose to sign their gym membership form or sign their workout schedule. In both examples, awareness of priming attempts will work towards successful decisions and consumption.

Given that our awareness instructions, which alerted participants not only to the prime but also to its potential effect on performance, it is reasonable to expect demand effects. The awareness manipulation itself could act similarly to a placebo effect. If this were the case, we would expect individuals in both analytic and holistic conditions to perform better. This was not the case; we observed 
no differences between the performance of individuals in the holistic unaware and those in the holistic aware condition. To rule out the possibility of demand effects of Study 1 we carried out Study 2.

\section{Study 2 - Reacting Against Negative Effects of Priming}

In Study 2, we work on further demonstrating that demand effects are not driving our results as well as examining how individuals respond to the prime when they believe that the effect is favorable or unfavorable. If individuals were consciously choosing to utilize the prime, then we would expect that the effect would still exist when participants believe the effect is positive, but that they would attempt to ignore or counteract the prime when the effect of it negatively affects their performance.

\section{Method}

Participants $(\mathrm{N}=114)$ completed the priming task (pronoun-circling task) on the subsequent Embedded Figures Test (EFT) described in study 1 in exchange for extra-credit in their undergraduate courses. Each participant of the experiment was randomly assigned to one of 2 (holistic vs. analytic thinking style) $\mathrm{x} 2$ (negative $v$ s. positive effect of the priming task) between-subjects conditions.

Mirroring study 1, participants in study 2 received instructions to read a paragraph about a trip to a city; those in the analytic condition were asked to circle pronouns representing the independent self (I, me), while those in the holistic condition were asked to circle pronouns representing the interdependent self (we, us). Unlike in our first study, all participants were aware of the effects of this pronoun-circling task on the proceeding task (EFT). However, participants read that either this subsequent effect would be positive (would enhance their performance in the proceeding task) or negative (would hinder their performance in the proceeding task). Specifically, individuals in positive conditions (both analytic and holistic) read instructions that included the following excerpt: "In order to help you perform better on the second task, in the first task, you will read a short paragraph about a trip to a city". Individuals assigned to negative conditions read a different set of instructions: "We are going to have you complete a task first that may hinder your performance on the second task. In the first task, you will read a short paragraph about a trip to a city".

After performing the pronoun-circling task (holistic or analytic prime), the participants proceeded with the same Embedded Figures Test (EFT) used in the first study. Finally, participants filled out selfreported measures of involvement, interest and effort (for both pronoun-circling and EFT tasks).

\section{Manipulation check}

Participants in our sample reported just as much involvement and interest with the tasks across both valence conditions (positive and negative), $F(1,112)<1, n s$. Participants also reported that they put as much effort in the pronoun-circling task, $F(1,112)<1$, ns, and in the EFT, $F(1,112)=2.95, n s$, across valence conditions. Furthermore, we measured the overall number of pronouns circled in the first task and considered it an objective measure of effort. Demotivated participants would likely circle fewer pronouns, regardless of the thinking style task (analytic or holistic). As expected, individuals in the negative valence condition circled as many pronouns as those in the positive condition, $F(1,112)<1, n s$.

\section{Results}

Unlike in Study 1, there is not a main effect of thinking style (analytic $v s$. holistic) on EFT scores, $F(1,110)<0.17, n s$. Valence (negative $v s$. positive) does not seem to influence EFT scores either. Individuals expecting the effects of the priming task to be positive did not perform any better than those expecting them to be negative, $F(1,110)=1.51, n s$. 
There is a significant two-way interaction between mindset (holistic and analytic) and valence of the priming manipulation (negative or positive), $F(1,110)=5.58, p<.05, \eta_{p}^{2}=.05$. For participants in the analytical thinking condition who believed the effect of the prime was positive, the prime manifests and performance in the EFT was higher. However, when the prime was believed to have a negative effect, participants were able to ignore or counteract the priming and EFT performance was suppressed, $M_{\text {analytic, positive }}=25.52, M_{\text {analytic, } \text {, egative }}=19.5, F(1,110)=6.57, p<.05, \eta_{p}^{2}=.05$.

However, only analytic thinking style increases performance at the Embedded Figures Test (Monga \& John, 2007; Nisbett et al., 2001). Individuals in the holistic condition, being told they would perform better (positive valence effect) or worse (negative valence effect) made no difference in their performance, $M_{\text {holistic, } \text {, positive }}=22.34, M_{\text {holistic, } \text {, egative }}=23.9, F(1,110)<1, n s$.

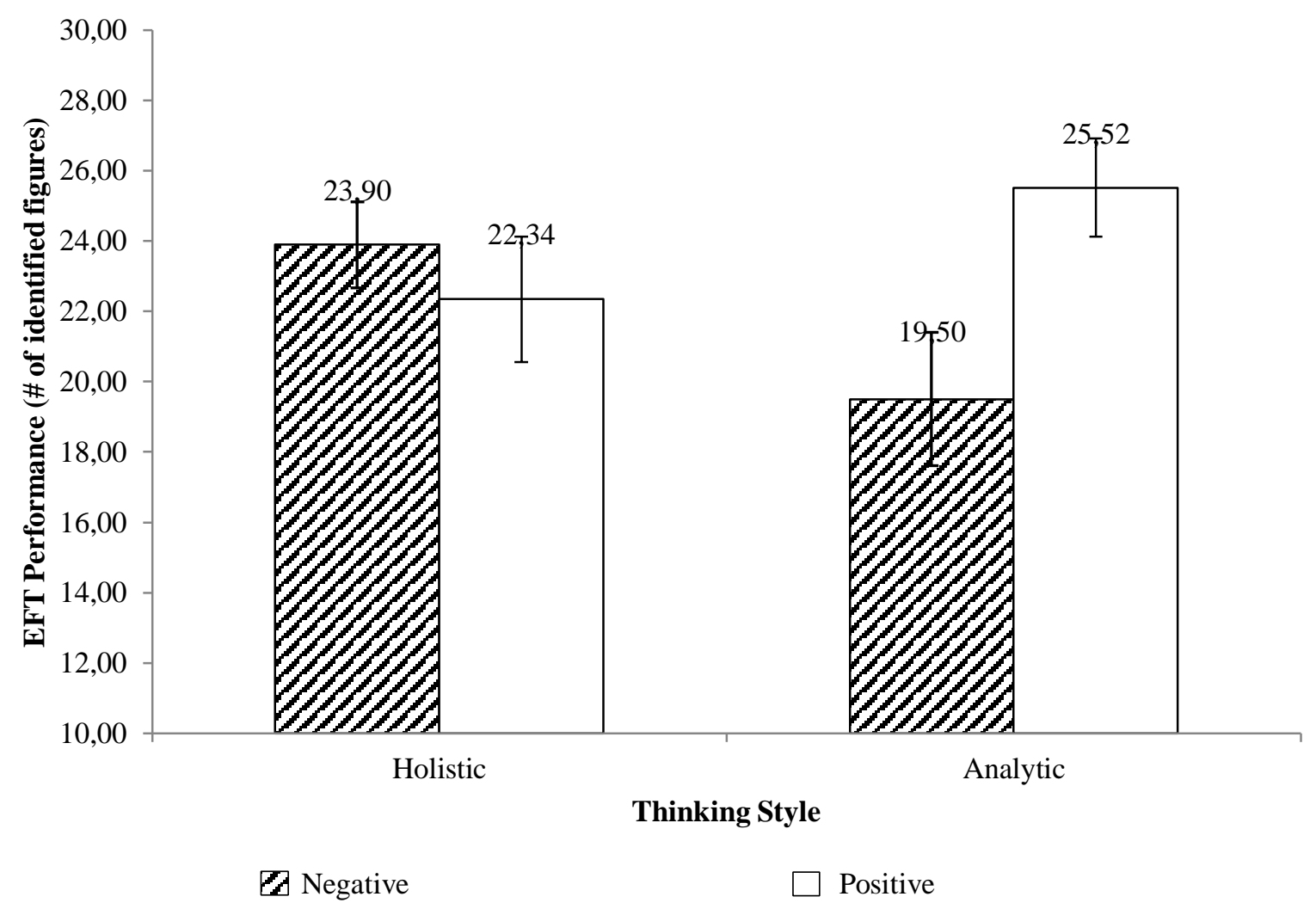

Figure 2. Performance on the Embedded Figures Test by Thinking Style and Valence of the Effect

Participants in both analytic and holistic thinking conditions were informed that the first task (pronoun-circling) would affect the second task (EFT) in either a positive (help subsequent performance) or negative (hinder subsequent performance) fashion. Telling our participants that they would perform better (worse) on a subsequent test only affected those in the analytical thinking style conditions. Individuals in the holistic thinking style conditions did not perform any differently, regardless of being told their performance would be better (worse). This pattern of results rules out possible demand and placebo effects.

This study also replicates our findings from Study 1. It brings evidences that, contrary to the wellestablished literature on correction (Devine, 1989; Lepore \& Brown, 2002), priming stimuli might be effective even if individuals are aware of their influence. This study also divorces this effect from possible demand effects, bringing new perspectives to the understanding on how consumers may react to priming. 


\section{General Discussion}

Our objective was to examine priming in a context in which the primed individual was conscious of the prime and where the prime had a positive effect. If the individual is motivated to perform better, then she is not motivated to attempt to counteract the effects of the prime. It is in her interest to attempt to utilize or even consciously bolster the effects of the prime. We demonstrate that individuals appear to be able to consciously prime the analytic mindset when this mindset increases their performance on a shape identification task.

Different types of consumption situations and decision processes can be associated with (and benefit from) the paper's conclusions, assuming that the effects of awareness of priming tasks on performance hold for other contexts. For example, thinking about yourself and how the product/service can improve your life - even in the case the product can be used by other people, such as when choosing a car for the family - should result in a more efficient decision process (i.e., faster, more precise, concentrated on key attributes). Interestingly, our results support the idea that this more efficient decision process would also persist in case of negative effects (e.g., the family being in debt due to a car loan).

Expanding our findings to the organizational side, such knowledge about priming can be used to configure different marketing actions, such as advertising, customer service, and customer relationship practices. Companies can easily adapt their offers and communications to include efficient decisionmaking priming tasks like the one we evidenced in this research. This allows them to work for and with customers, instead of against customers, which is the prevailing popular view of priming (Lindstrom, 2011).

More broadly, our work suggests that conscious priming may work when attempting to establish a way of systematic thinking, a mindset. This does not have to be limited to holistic/analytic. Other mindsets such as implicit theories of the self (i.e. whether someone sees traits as fixed or malleable), creative mindsets, and regulatory focus mindsets may also be capable of intentional conscious priming. There may be also other frameworks besides mindsets where conscious priming may be effective. For example, we can also prime incomplete ideas or tasks that we wish to address later. Individuals could employ a conscious priming strategy to utilize incubation periods in creativity (Ellwood, Pallier, Snyder, $\&$ Gallate, 2009). They can even try to prime the unconscious processing in the gut decision research that shows that unconscious processing (with delay) is sometimes better than conscious processing (Dijksterhuis, 2004). Of course, sometimes it might be difficult for consumers to consciously prime an idea and then intentionally try to think about other information, similar to the ironic processing demonstrated by Wegner (1989) in which once people are told not to think about a white bear it is difficult not to do so.

There may be many additional occasions where conscious priming cannot be evoked. Conscious priming most likely would not work for effects based upon systematic, bias-based effects (e.g. anchoring) or effects based upon self-deception (e.g. placebo effects). Our findings elicit a natural comparison to placebo effects. One distinction that our research may allow us to draw between primes and placebos is their relative invulnerability to individuals' awareness. Our primes do not rely on individuals believing that they are efficacious, just that they are not inhibitory. In contrast, placebos traditionally work based on the deception that an efficacious treatment has been applied. If individuals are made aware that the treatment was fictitious, then the effect tends to be attenuated. However, some recent work has shown that if the placebo is used as a prime for the power of positive thinking, then awareness of the effect does not cause it to disappear (Kaptchuk et al., 2010). It may be that when highly motivated, individuals are able to prime and deceive themselves even when faced against conflicting evidence. This conclusion is especially important, but not limited, to consumption decisions of high involvement. Highly involved consumers can benefit from the gains of a more efficient decision process after such priming efforts. 


\section{Conclusion, Limitations, and Future Research}

Our end objective would be to develop techniques that enable consumers to prime themselves in every day scenarios to improve task performance and reach their desired goals. This would require them to successfully complete two related tasks: they must not only know how to apply the prime but also recognize when to apply it. This research is not aimed at answering these two questions, and future research should study both of these issues. First, can we train consumers to recognize situations when one framework may be more effective to reach their goal than another may? It is only then we can address whether consumers are able to learn priming techniques and successfully apply them without marketer intervention.

Future studies might also consider broadening the scope of the sample. This is a set of lab experiments with college students that, along with the necessary benefits of control and internal validity, carries the limitations of a narrowly defined sample.

Considering the company side, future research should also evaluate how to develop priming strategies based on consumers' profiles and levels of involvement to generate more efficient decision processes. We have not tested such priming effects under real life situations, but our results suggest that such outcomes could be achieved. More efficient decisions will lead to greater customer satisfaction, greater consumer happiness and less regret, which, in turn, are associated with increased repurchasing behavior, more positive attitudes and, consequently, sustainable long-term profits.

\section{References}

Bargh, J. A. (1989). Conditional automaticity: varieties of automatic influence in social perception and cognition. In J. S. Uleman (Ed.), Unintended thought (pp. 3-51). New York, NY: Guilford Press.

Bargh, J. A. (1992). Does subliminality matter to social psychology? Awareness of the stimulus versus awareness of its influence. In R. F. Bornstein \& T. S. Pittman (Eds.), Perception without awareness: cognitive, clinical, and social perspectives (pp. 236-255). New York: Guilford Press.

Bargh, J. A. (1994). The four horsemen of automaticity: awareness, intention, efficiency, and control in social cognition. In R. S. Wyer \& T. K. Srull (Eds.), Handbook of social cognition: basic processes (pp. 1-40). Hillsdale, NJ: Lawrence Erlbaum Associates.

Bargh, J. A., \& Chartrand, T. L. (1999). The unbearable automaticity of being. American Psychologist, 54(7), 462-479. doi: 10.1037/0003-066X.54.7.462

Brewer, M. B., \& Gardner, W. (1996). Who is this "we"? Levels of collective identity and self representations. Journal of Personality and Social Psychology, 71(1), 83-93. doi: 10.1037/00223514.71.1.83

Chartrand, T. L., \& Bargh, J. A. (1996). Automatic activation of impression formation and memorization goals: nonconscious goal priming reproduces effects of explicit task instructions. Journal of Personality and Social Psychology, 71(3), 464-478. doi: 10.1037/0022-3514.71.3.464

Chartrand, T. L., Huber, J., Shiv, B., \& Tanner, R. J. (2008). Nonconscious goals and consumer choice. Journal of Consumer Research, 35(2), 189-201. doi: 10.1086/588685

Desmeules, R. (2002). The impact of variety on consumer happiness: marketing and the tyranny of freedom. Academy of Marketing Science Review, 12(1), 1-18. 
Devine, P. G. (1989). Stereotypes and prejudice: their automatic and controlled components. Journal of Personality and Social Psychology, 56(1), 5-18. doi: 10.1037/0022-3514.56.1.5

Dhar, R., \& Kim, E. (2007). Seeing the forest or the trees: implications of construal level theory for consumer choice. Journal of Consumer Psychology, 17(2), 96-100. doi: 10.1016/S10577408(07)70014-1

Dijksterhuis, A. (2004). Think different: the merits of unconscious thought in preference development and decision making. Journal of Personality and Social Psychology, 87(5), 586-598. doi: $10.1037 / 0022-3514.87 .5 .586$

Ellwood, S., Pallier, G., Snyder, A., \& Gallate, J. (2009). The incubation effect: hatching a solution? Creativity Research Journal, 21(1), 6-14. doi: 10.1080/10400410802633368

Fitzsimons, G. M., Chartrand, T. L., \& Fitzsimons, G. J. (2008). Automatic effects of brand exposure on motivated behavior: how apple makes you "think different". Journal of Consumer Research, 35(1), 21-35. doi: 10.1086/527269

Forehand, M. R., \& Deshpandé, R. (2001). What we see makes us who we are: priming ethnic selfawareness and advertising response. Journal of Marketing Research, 38(3), 336-348. doi: 10.1509/jmkr.38.3.336.18871

Gardner, W. L., Gabriel, S., \& Lee, A. Y. (1999). "I" value freedom, but “we” value relationships: selfconstrual priming mirrors cultural differences in judgment. Psychological Science, 10(4), $321-$ 326. doi: $10.1111 / 1467-9280.00162$

Heath, C., \& Soll, J. B. (1996). Mental budgeting and consumer decisions. Journal of Consumer Research, 23(1), 40-52. doi: 10.1086/209465

Horn, W. (1962). Leistungsprüfsystem, L-P-S: Handanweisung für die Durchführung, Auswertung und Interpretation./ A performance testing system: Manual for administration, scoring, and interpretation. Oxford, England: Oxford.

Irwin, J. R., \& McClelland, G. H. (2001). Misleading heuristics and moderated multiple regression models. Journal of Marketing Research, 38(1), 100-109. doi: 10.1509/jmkr.38.1.100.18835

Janiszewski, C., \& Wyer, R. S. (2014). Content and process priming: a review. Journal of Consumer Psychology, 24(1), 96-118. doi: 10.1016/j.jcps.2013.05.006

Kaptchuk, T. J., Friedlander, E., Kelley, J. M., Sanchez, M. N., Kokkotou, E., Singer, J. P., Kowalczykowski, M., Miller, F. G., Kirsch, I., \& Lembo, A. J. (2010). Placebos without deception: a randomized controlled trial in irritable bowel syndrome. PloS One, 5(12), e15591. doi: 10.1371/journal.pone.0015591

Kettle, K. L., \& Häubl, G. (2011). The signature effect: signing influences consumption-related behavior by priming self-identity. Journal of Consumer Research, 38(3), 474-489. doi: 10.1086/659753

Kühnen, U., Hannover, B., \& Schubert, B. (2001). The semantic-procedural interface model of the self: the role of self-knowledge for context-dependent versus context-independent modes of thinking. Journal of Personality and Social Psychology, 80(3), 397-409. doi: 10.1037/0022-3514.80.3.397

Kunst-Wilson, W. R., \& Zajonc, R. B. (1980). Affective discrimination of stimuli that cannot be recognized. Science, 207(4430), 557-558. doi: 11.1126/science.7352271

Laran, J., Dalton, A. N., \& Andrade, E. B. (2011). The curious case of behavioral backlash: why brands produce priming effects and slogans produce reverse priming effects. Journal of Consumer Research, 37(6), 999-1014. doi: 10.1086/656577 
Lashley, K. S. (1951). The problem of serial order in behavior. In L. A. Jeffress (Ed.), Cerebral mechanisms in behavior: the hixon symposium (pp. 112-136). New York: Wiley \& Sons.

Lepore, L., \& Brown, R. (2002). The role of awareness: divergent automatic stereotype activation and implicit judgment correction. Social Cognition, 20(4), 321-351. doi: 10.1521/soco.20.4.321.19907

Lerman, D., \& Shefrin, H. (2015). Positive marketing: introduction to the special section. Journal of Business Research, 68(12), 2443-2445. doi: 10.1016/j.jbusres.2015.06.030

Lindstrom, M. (2011). Brandwashed: tricks companies use to manipulate our minds and persuade us to buy. New York: Crown Publishing Group.

Lombardi, W. J., Higgins, E. T., \& Bargh, J. A. (1987). The role of consciousness in priming effects on categorization: assimilation versus contrast as a function of awareness of the priming task. Personality and Social Psychology Bulletin, 13(3), 411-429. doi: 10.1177/0146167287133009

Martin, L. L. (1986). Set/reset: use and disuse of concepts in impression formation. Journal of Personality and Social Psychology, 51(3), 493-504. doi: 10.1037/0022-3514.51.3.493

Meyers-Levy, J., \& Zhu, R. (2007). The influence of ceiling height: the effect of priming on the type of processing that people use. Journal of Consumer Research, 34(2), 174-186. doi: 10.1086/519146

Monga, A. B., \& John, D. R. (2007). Cultural differences in brand extension evaluation: the influence of analytic versus holistic thinking. Journal of Consumer Research, 33(4), 529-536. doi: $10.1086 / 510227$

Monga, A. B., \& John, D. R. (2008). When does negative brand publicity hurt? The moderating influence of analytic versus holistic thinking. Journal of Consumer Psychology, 18(4), 320-332. doi: $10.1016 /$ j.jcps.2008.09.009

Nisbett, R. E., Peng, K., Choi, I., \& Norenzayan, A. (2001). Culture and systems of thought: holistic versus analytic cognition. Psychological Review, 108(2), 291-310. doi: 10.1037/0033295X.108.2.291

Rosenthal, R., \& Rosnow, R. (2007). Essentials of behavioral research: methods and data analysis. New York: McGraw-Hill Companies.

Schwartz, B. (2009). The paradox of choice. New York: Harper Collins.

Shiv, B., \& Fedorikhin, A. (1999). Heart and mind in conflict: the interplay of affect and cognition in consumer decision making. Journal of Consumer Research, 26(3), 278-292. doi: 10.1086/209563

Storms, L. H. (1958). Apparent backward association: a situational effect. Journal of Experimental Psychology, 55(4), 390-395. doi: 10.1037/h0044258

Strack, F., Schwarz, N., Bless, H., Kübler, A., \& Wänke, M. (1993). Awareness of the influence as a determinant of assimilation versus contrast. European Journal of Social Psychology, 23(1), 5362. doi: $10.1002 /$ ejsp. 2420230105

Wathieu, L., Brenner, L., Carmon, Z., Chattopadhyay, A., Wertenbroch, K., Drolet, A., Gourville, A., Muthukrishnan, A. V., Novemsky, A., Ratner, R. K., \& Wu, G. (2002). Consumer control and empowerment: a primer. Marketing Letters, 13(3), 297-305. doi: 10.1023/A:1020311914022

Wegner, D. M. (1989). White bears and other unwanted thoughts. New York, NY: Viking. 
Wyer, R. S. (2008). The role of knowledge accessibility in cognition and behavior. In C. P. Haugtvedt, P. M. Herr, \& F. R. Kardes (Eds.), Handbook of consumer psychology (pp. 31-76). New York, NY: Psychology Press.

\section{Authors' Profiles}

Leonardo Nicolao

Rua Washington Luiz, 855, 90040-060, Porto Alegre, RS, Brazil. E-mail address: leonardo.nicolao@ufrgs.br; nicolao@utexas.edu

Eric Yorkston

Neeley School of Business, TCU Box 298530, Fort Worth, 76129, Texas, United States. E-mail address: e.yorkston@tcu.edu

Deanne Brocato

Management Department, 3500 Old Main Hill Logan, 84322-3500, Logan, Utah, United States. E-mail address: deanne.brocato@usu.edu

Vinicius Andrade Brei

Rua Washington Luiz, 855, 90040-060, Porto Alegre, RS, Brazil. E-mail address: brei@ufrgs.br 